\title{
Testing the importance of jasmonate signalling in induction of plant defences upon cabbage aphid (Brevicoryne brassicae) attack
}

\author{
Anna Kuśnierczyk', Diem HT Tran¹, Per Winge', Tommy S Jørstad², John C Reese ${ }^{3}$, Joanna Troczyńska ${ }^{4}$ and
} Atle M Bones ${ }^{1 *}$

\begin{abstract}
Background: Phloem-feeding aphids deprive plants of assimilates, but mostly manage to avoid causing the mechanical tissue damage inflicted by chewing insects. Nevertheless, jasmonate signalling that is induced by infestation is important in mediating resistance to phloem feeders. Aphid attack induces the jasmonic acid signalling pathway, but very little is known about the specific impact jasmonates have on the expression of genes that respond to aphid attack.

Results: We have evaluated the function that jasmonates have in regulating Arabidopsis thaliana responses to cabbage aphid (Brevicoryne brassicae) by conducting a large-scale transcriptional analysis of two mutants: aos, which is defective in jasmonate production, and fou2, which constitutively induces jasmonic acid biosynthesis. This analysis enabled us to determine which genes' expression patterns depend on the jasmonic acid signalling pathway. We identified more than 200 genes whose expression in non-challenged plants depended on jasmonate levels and more than 800 genes that responded differently to infestation in aos and fouz plants than in wt. Several aphid-induced changes were compromised in the aos mutant, particularly genes connected to regulation of transcription, defence responses and redox changes. Due to jasmonate-triggered pre-activation of fouz, its transcriptional profile in non-challenged plants mimicked the induction of defence responses in wt. Additional activation of fouz upon aphid attack was therefore limited. Insect fitness experiments revealed that the physiological consequences of fouz mutation contributed to more effective protection against B. brassicae. However, the observed resistance of the fou 2 mutant was based on antibiotic rather than feeding deterrent properties of the mutant as indicated by an analysis of aphid feeding behaviour.

Conclusions: Analysis of transcriptional profiles of wt, aos and fou 2 plants revealed that the expression of more than 200 genes is dependent on jasmonate status, regardless of external stimuli. Moreover, the aphid-induced response of more than 800 transcripts is regulated by jasmonate signalling. Thus, in plants lacking jasmonates many of the defence-related responses induced by infestation in wt plants are impaired. Constant up-regulation of jasmonate signalling as evident in the four mutant causes reduction in aphid population growth, likely as a result of antibiotic properties of fou 2 plants. However, aos mutation does not seem to affect aphid performance when the density of B. brassicae populations on plants is low and aphids are free to move around.
\end{abstract}

Keywords: aphid, gene expression, infestation, jasmonic acid signalling, microarrays, plant defence, EPG

\footnotetext{
* Correspondence: atle.bones@bio.ntnu.no

'Department of Biology, The Norwegian University of Science and

Technology, Realfagbygget, 7491 Trondheim, Norway

Full list of author information is available at the end of the article
} 


\section{Background}

Jasmonates, including jasmonic acid (JA) and the biologically active intermediates and derivatives of the JA biosynthetic pathway, are powerful regulators of plant development and inducible resistance. By mediating signal transduction they influence changes in expression profiles of a wide range of genes involved in plant defence [1]. Induction of JA-related response has often been linked to tissue damage, and the important roles of JA signalling in defence against bacterial and fungal infections or caterpillar attack are well documented (for reviews [2-4]). More recent research, however, provides evidence for the activation of JA-mediated defence upon attack by phloem-sucking insects, such as aphids and silverleaf whitefly nymphs, which try to avoid tissue damage during feeding [5-10]. Phloem feeders possess stylet-like mouthparts, which they use to ingest phloem sap. During penetration of plant tissue the stylet is manoeuvred through plant tissue until it is finally anchored in a sieve tube element. Here it can stay for several hours or even days, facilitating a continuous sap supply. By avoiding extensive tissue wounding, aphids minimize the risk of inducing defence responses in the attacked plant while depriving it of assimilates. In the case of a massive infestation, the loss of nutrients interferes with plant growth and development, and may eventually lead to plant death. Constitutive or transient activation of JA-related responses is known to enhance a plant's resistance to phloem feeders, including aphids [11-13].

JA is biosynthesized from polyunsaturated fatty acids released from chloroplast membranes via a series of enzymatic reactions usually referred to as the octadecanoid pathway. In pathogen-free laboratory conditions, a nonfunctional JA pathway does not result in any disturbance in normal vegetative growth. In a more natural environment, however, mutant plants that do not synthesize JA are more susceptible to pathogen attack because they fail to activate JA-dependent defences [14]. A knock-out mutation of the allene oxide synthase (AOS) gene, whose product is an enzyme essential for the synthesis of 12-oxophytodienoic acid (OPDA), a precursor for the synthesis of JA, results in a phenotype unable to produce JA or any JA derivatives [15] (Additional file 1 Figure S1). AtAOS is a single-copy gene, and no alternative enzymes possessing the same catalytic activity have been found in Arabidopsis [16]. Thus, the induction of JA-dependent genes is impaired in the aos mutant [15].

The fatty acid oxygenation up-regulated 2 (fou2) mutant was isolated by Bonaventure and co-workers in a search for plants with increased activity of two key JA biosynthetic enzymes: lipoxygenase (LOX) and AOS. JA and OPDA levels are almost doubled in non-challenged fou 2 plants compared to wt [17] (Additional file 1 Figure S1).
The fou 2 allele carries a missense mutation resulting in an amino acid substitution in the Two Pore Channel 1 (TPC1) protein (encoded by At4g03560) [17]. TPC1 forms a non-specific, slowly activating, $\mathrm{Ca}^{2+}$-regulated cation channel in vacuolar membranes [18]. In fou 2 the TPC1 channel has different electrophysiological properties: lower voltage is required for its activation and its time-dependent conductivity is higher than in wt [17]. Probably due to the increased sensitivity of voltage sensors in the mutated TPC1, the activation of the JA biosynthetic pathway upon wounding is stronger in fou 2 plants and the levels of free JA and OPDA are higher in the mutant relative to wt [17].

Transcriptional analyses of aphid-infested Arabidopsis plants have revealed substantial changes in the expression profiles of many defence-related genes [7,9,19-21]. Several genes whose products are involved in JA synthesis or JA-dependent signalling have been reported to be up-regulated, indicating that JA-derived compounds play a role in the regulation of expressional changes. As a result of transcriptional reprogramming, the production of proteins involved in defence is promoted [22] and the metabolite profiles of plants are changed [7,23-25]. Despite significant progress in our understanding of plant responses triggered by phloem feeders attack (for reviews: [26-30]), it is largely unknown how much the induction of these defences relies on JA signalling.

In this study, we provide new insights into the role of jasmonates in the regulation of defence responses upon aphid attack. A specialized phloem feeder is represented by the cabbage aphid, Brevicoryne brassicae, for which a model of Arabidopsis-aphid interactions has been well established [8]. Our aim is to identify the genes whose expressional changes are controlled by JA signalling. The subsequent parts of this work concentrate on the following problems: Which genes are primarily dependent on jasmonates for their expression? How is the aphidinduced plant defence affected by the absence of JA or the constitutive up-regulation of the JA pathway? How does the impact of the aos and fou 2 mutations affect aphid performance? To address these problems we have performed transcriptional profiling of both aphid-challenged and non-challenged wild type plants as well as aos and fou 2 mutants using full genome oligonucleotide microarrays. Further, insect fitness experiments and Electrical Penetration Graph analysis have been undertaken to determine how the JA status of the host plants influences the survival and behaviour of insects.

\section{Results}

To investigate the importance of JA signalling in transcriptional reprogramming of $A$. thaliana triggered by aphid attack, we designed an experiment that included 
comparisons of genome-wide transcription profiles at three levels (Figure 1). Each level was comprised of a series of microarray hybridizations exploring transcriptional changes in at least three biological replicates per comparison. At the first level, which we regard as the basic comparison, we aimed to identify and classify genes that are dependent on jasmonates for their basic expression. This was done by comparing the transcription profiles of non-challenged wt plants and the two mutants, aos and fou2. At the second level the changes in transcriptional activity resulting from $72 \mathrm{~h}$ of aphid infestation of wt, aos and fou 2 plants were analysed in each of the three lines independently. At the third level we directly compared aphid-induced transcriptional changes in each of the mutants with the corresponding changes in wt plants. The microarray data generated at all three levels were used in the statistical analysis. Twelve genes that were particularly interesting due to their involvement in JA signalling and/or their association with plant defence responses were further selected for $\mathrm{qRT}-\mathrm{PCR}$ analysis. The gene expression profiles revealed by qRT-PCR analysis seem to correspond well to the profiles obtained from microarray data (Additional file 2 Figure S2).

\section{Identification of genes regulated by the JA signalling pathway}

Both aos and fou 2 mutations have a great impact on the regulation of the JA biosythesis pathway regardless of environmental conditions (Figure 2). Therefore, before investigation of genes whose transcriptional regulation in response to $B$. brassicae attack is controlled by JA signalling, we aimed to identify the genes whose basic expression in non-challenged plants is modified according to endogenous JA levels. The following criteria have been adopted to identify jasmonate-dependent genes. To be considered positively regulated by jasmonates, a gene had to be down-regulated in aos ( $\log 2$ ratio <-0.5) and upregulated in fou $2(\log 2$ ratio $>0.5)$ as compared to wt. Conversely, the expression of genes classified as negatively regulated by jasmonates was positively affected in aos and negatively affected in fou 2 , respectively. One-hundred seventy-two genes were found to be positively regulated by jasmonates and have been classified into the following functional gene classes: transcripts involved in JA synthesis and JA signalling, defence-related proteins including myrosinases and myrosinase binding or associated proteins, genes whose products are involved in the regulation of transcription, redox balance, cell wall modification, protein modification, nucleoside/nucleotide metabolism, transport and lipid metabolism (Additional file 3 Table S1). Among the 39 genes whose expression was negatively regulated by jasmonates were several transcription regulators, genes coding for proteins with ankyrin repeats and connected to redox status. Except for genes with unknown functions, other categories were represented by only 1-2 members (Additional file 4 Table S2).

As JA signalling is important in the regulation of plant defensive responses triggered by aphid attack we expected to observe the effect of the changed JA status on the expression of aphid-responsive genes. It should be noted that not all genes classified by us as JA dependent were found to be responsive to B. brassicae attack. Although a number of JA-dependent genes were induced
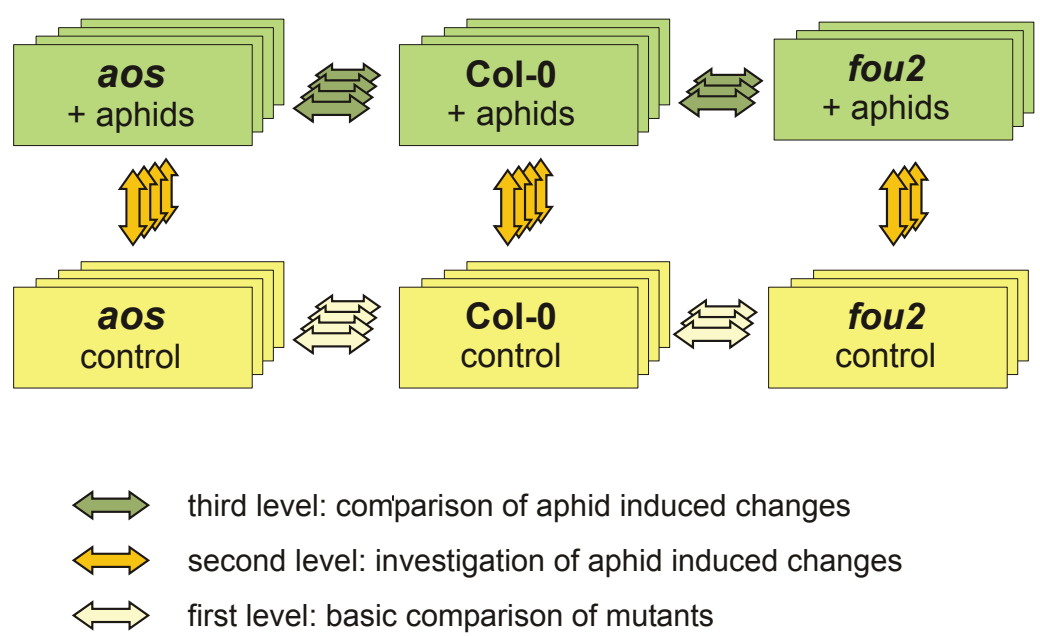

Figure 1 Microarray experimental design. Each square represents one biological replicate consisting of control, non-infested plants (yellow) or plants that have been subjected to 72 hours of infestation with Brevicoryne brassicae (green). Each arrow represents a direct comparison with the use of one microarray slide. The experiment was designed to assess three levels of comparisons: the first explores basic transcriptional profiles of non-infested mutants vs. wt plants (yellow arrows), the second aims to measure gene expression changes after aphid attack (orange arrows), while the third investigates the differences in the transcriptional reprogramming of mutants and wt plants (green arrows). 


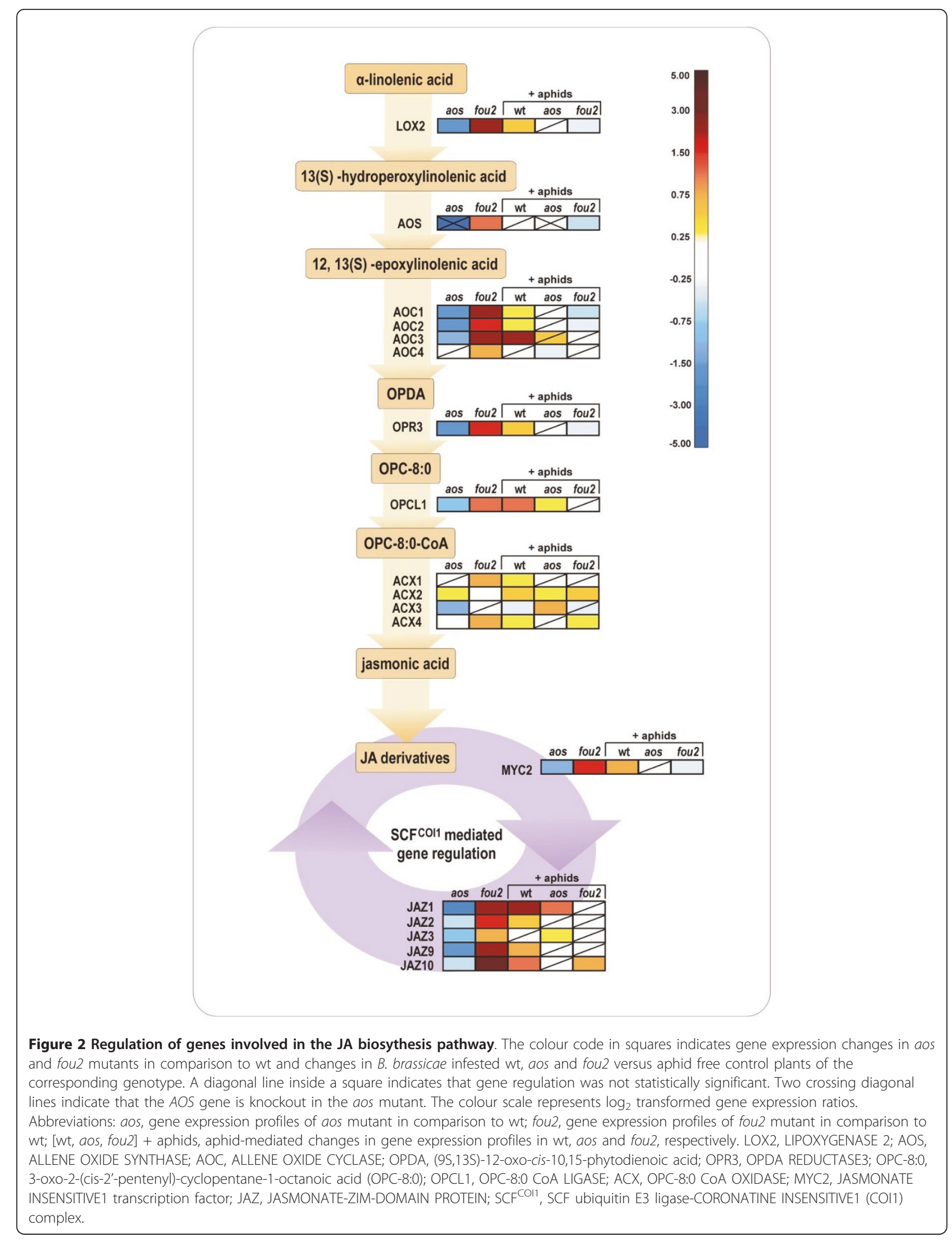


by $B$. brassicae in wt plants, their aphid-mediated induction was impaired not only in aos, as expected, but also in fou 2 plants. This was the case for several transcripts whose products are involved either in the biosynthesis of JA or in JA-mediated signalling (Figure 2), defencerelated genes, transcription factors and redox homeostasis. Table 1 summarizes expression profiles of all genes that have been classified by us as JA dependent and whose responsiveness to $B$. brassicae attack was changed in aos or fou 2 mutants relative to wt.
JA signalling has an overall significant impact on the regulation of Arabidopsis thaliana responses to Brevicoryne brassicae attack

Among all aphid responsive genes that have been classified as JA dependent in non-infested plants, the majority were found to have altered responsiveness to B. brassicae attack in the mutants compared to wt (Table 1). However, several other genes that did not change expression in non-challenged aos and fou 2 displayed unique responses to aphid infestation in the mutant

Table 1 Jasmonate-dependent genes whose responsiveness to $B$. brassicae attack was changed in aos or fou 2 mutants relative to wt

\begin{tabular}{|c|c|c|c|c|c|c|}
\hline \multirow[b]{2}{*}{ Gene } & \multirow[b]{2}{*}{ Accession } & \multirow[b]{2}{*}{$a o s / w t$} & \multirow[b]{2}{*}{ fou $2 /$ wt } & \multicolumn{3}{|c|}{ Infested with Brevicoryne brassicae } \\
\hline & & & & wt $B / w t$ & aosB/aos & fou $2 B /$ fou 2 \\
\hline \multicolumn{7}{|l|}{ JA synthesis } \\
\hline LOX2 & At3g45140 & -1.97 & 2.09 & 0.55 & NS & -0.42 \\
\hline $\mathrm{AOC} 3$ & At3g25780 & -1.26 & 2.36 & 2.19 & NS & NS \\
\hline OPR3 & At2g06050 & -1.51 & 1.62 & 0.52 & NS & -0.47 \\
\hline OPCL1 & At1g20510 & -0.77 & 1.13 & 1.08 & 0.29 & NS \\
\hline \multicolumn{7}{|l|}{ JA signalling } \\
\hline CORI3 & At4g23600 & -1.60 & 2.42 & 0.83 & NS & NS \\
\hline MYC2 (JIN1) & At1g32640 & -1.45 & 1.86 & 0.91 & NS & -0.43 \\
\hline JAZ1 & At1g19180 & -2.31 & 2.62 & 2.10 & 1.15 & NS \\
\hline JAZ2 & At1g74950 & -0.55 & 1.89 & 0.69 & NS & NS \\
\hline JAZ6 & At1g72450 & -1.41 & 2.00 & 0.58 & NS & NS \\
\hline JAZ9 & At1g70700 & -1.99 & 2.65 & 0.79 & NS & NS \\
\hline JAZ10 & At5g13220 & -0.85 & 3.69 & 1.10 & NA & 0.91 \\
\hline \multicolumn{7}{|l|}{ Defence } \\
\hline PDF1.2 & At5g44420 & -3.33 & 3.53 & 2.99 & NS & NS \\
\hline PDF1.2b & At2g26020 & -3.53 & 3.31 & 3.00 & NS & NS \\
\hline PDF1.3 & At2g26010 & -3.46 & 3.23 & 2.80 & NS & NS \\
\hline PDF1.2C & At5g44430 & -3.32 & 3.23 & 2.70 & NS & NS \\
\hline AFP1 & At1g75830 & -3.04 & 3.40 & 2.64 & NS & NS \\
\hline S-adenosylmethionine-dependent methyltransferase & At3g44870 & -1.45 & 3.13 & 1.91 & NS & NS \\
\hline MBP1 & At1g52040 & -2.53 & 4.98 & 0.73 & NS & NS \\
\hline S-adenosylmethionine-dependent methyltransferase & At3g44860 & -1.27 & 2.60 & 0.98 & NS & -0.86 \\
\hline arginase & At4g08870 & -1.44 & 4.05 & 0.94 & NS & -0.63 \\
\hline strictosidine synthase & At3g51450 & -1.18 & 1.70 & 0.55 & -1.01 & NS \\
\hline EDS5 & At4g39030 & -0.52 & 0.87 & 1.87 & 1.15 & NS \\
\hline ASA1 & At5g05730 & -0.70 & 0.73 & 1.08 & 0.64 & 0.53 \\
\hline TAT3 & At2g24850 & -1.58 & 3.52 & 4.20 & 2.03 & NS \\
\hline CYP79B2 & At4g3995 & -0.83 & 1.17 & 1.41 & 1.15 & 0.47 \\
\hline PR4 & At3g04720 & -0.81 & 1.35 & 2.32 & 0.76 & 1.13 \\
\hline trypsin inhibitor 1 (ATTI1) & At2g43510 & -1.08 & 3.71 & 1.74 & 0.86 & 1.14 \\
\hline trypsin inhibitor & At1g73260 & -1.65 & 2.85 & 1.00 & 1.44 & 1.62 \\
\hline protease inhibitor (LTP) & At5g48490 & -0.64 & 0.79 & -0.79 & -0.67 & -0.98 \\
\hline HSP17.4-CIII & At1g54050 & -0.95 & 0.81 & -0.67 & -0.59 & -0.55 \\
\hline \multicolumn{7}{|l|}{ Transcription factors } \\
\hline WRKY75 & At5g13080 & -1.82 & 2.52 & 3.23 & 3.18 & 1.31 \\
\hline ERF2 & At5g47220 & -1.13 & 0.88 & 2.06 & 1.02 & 0.42 \\
\hline RHL41/ZAT12 & At5g59820 & -1.39 & 1.85 & 3.02 & 2.26 & NS \\
\hline
\end{tabular}


Table 1 Jasmonate-dependent genes whose responsiveness to B. brassicae attack was changed in aos or fou2 mutants relative to wt (Continued)

\begin{tabular}{|c|c|c|c|c|c|c|}
\hline HSF6 & At5g62020 & -0.90 & 1.05 & 0.64 & 0.81 & NS \\
\hline \multicolumn{7}{|l|}{ Redox } \\
\hline Atperox P37 & At4g08770 & -1.46 & 1.08 & 1.57 & 1.36 & 1.41 \\
\hline GST22/ATGSTU4 & At2g29460 & -0.73 & 0.99 & 1.87 & 1.20 & 1.05 \\
\hline MDAR4 & At5g03630 & -0.75 & 0.62 & 0.67 & 0.44 & NS \\
\hline Atperox P32 & At3g32980 & -1.49 & 1.38 & -0.82 & 0.43 & NS \\
\hline FRO6 & At5g49730 & -0.84 & 0.70 & -0.76 & 0.46 & -1.25 \\
\hline copper amine oxidase & At1g31710 & -1.56 & 1.00 & -1.17 & 0.65 & NS \\
\hline \multicolumn{7}{|l|}{ Auxin synthesis } \\
\hline ILL4 & At1g51760 & -0.70 & 1.71 & 1.84 & NS & NS \\
\hline NIT2 & At3g44300 & -0.82 & 2.10 & 1.20 & 0.95 & 1.68 \\
\hline \multicolumn{7}{|l|}{ cell wall modification } \\
\hline PGIP2 & At5g06870 & -0.90 & 2.72 & 0.63 & NS & 0.70 \\
\hline AGP & At1g03820 & -0.55 & 2.81 & NS & 0.57 & 1.53 \\
\hline FLR1 & At3g12145 & -0.91 & 2.04 & -0.58 & 0.53 & 0.60 \\
\hline invertase/pectin methylesterase inhibitor & At1g62770 & -1.30 & 0.87 & -1.01 & 1.63 & 1.18 \\
\hline \multicolumn{7}{|l|}{ lipid metabolism } \\
\hline esterase/lipase/thioesterase family protein & At2g39420 & -0.77 & 2.29 & 1.60 & NS & NS \\
\hline \multicolumn{7}{|l|}{ unknown } \\
\hline unknown plant specific protein (AR781) & At2g26530 & -0.53 & 1.36 & 1.31 & 0.39 & NS \\
\hline
\end{tabular}

The values in the table represent $\log _{2}$ transformed gene expression changes for the following comparisons: aos/wt, change in a gene expression level in aos mutant in comparison to wt; fou2/wt, change in a gene expression level in fou 2 mutant in comparison to wt; wtB/wt, change in a gene expression level in wt plants attacked by aphids in comparison to aphid-free wt controls; aosB/aos, change in a gene expression level in aos plants attacked by aphids in comparison to aphid-free aos controls; fou2B/fou2, change in a gene expression level in fou 2 plants attacked by aphids in comparison to aphid-free fou 2 controls; NS, not statistically significantly regulated.

plants. A list of genes responding differently to B. brassicae attack in a given mutant was created based on the following criteria: (i) the aphid-induced regulation of a given gene had to be statistically significant for at least one of the two compared genotypes (e.g. for the given mutant or for wt); (ii) the difference in the aphidinduced gene regulation (expressed in $\log _{2}$ ratio) between the two compared genotypes had to be larger than one. The complete lists of genes fulfilling these requirements are presented in Additional files 5, 6, 7, 8 Tables S3, S4, S5 and S6 while Figure 3 represents the distribution of functional categories among the differentially responding genes in the two mutants. Although, as expected, the aphid-induced responsiveness of many genes was changed in the mutants relative to wt, the direction of the observed changes was surprisingly similar in the aos and fou 2 mutants. For example, the relatively large groups of genes related to defence and regulation of transcription were less responsive to infestation both in aos and fou 2 (Figure 3). Similarly, among genes identified as more responsive to aphids in the mutants than in wt, transcripts connected to transport, cell wall modification, cell division and development and cytoskeleton organisation were more induced in both mutants (Figure 3). To evaluate an overall impact of the aos and fou 2 mutations on the different functional gene categories of aphid-responsive genes, GO Term Enrichment analysis was performed with the use of AmiGO Term Enrichment software [31]. Four sets of genes that responded differentially to $B$. brassicae infestation (corresponding to Additional files 5, 6, 7, 8 Tables S3, S4, S5 and S6) were annotated with Gene Ontology terms and AmiGo was used to determine whether the observed levels of annotation for the particular sets were significant in the context of a background set (i.e. all $A$. thaliana genes that have been attributed to a particular GO term). The statistically significantly overrepresented GO terms connected to Biological Process and Molecular Function nodes were then visualized according to significance level and the numbers of genes attributed to linked GO terms were given separately for aos and fou 2 mutants (Figure 4).

\section{B. brassicae induced regulation of transcription factors and defence-related genes is largely controlled by JA signalling}

The JA signalling pathway is believed to significantly contribute to the regulation of defence-connected genes under stress conditions. The GO terms denoted "transcription regulation activity" and "response to stress" with the sub-nodes "defence responses" and "response to wounding" were statistically significantly overrepresented 


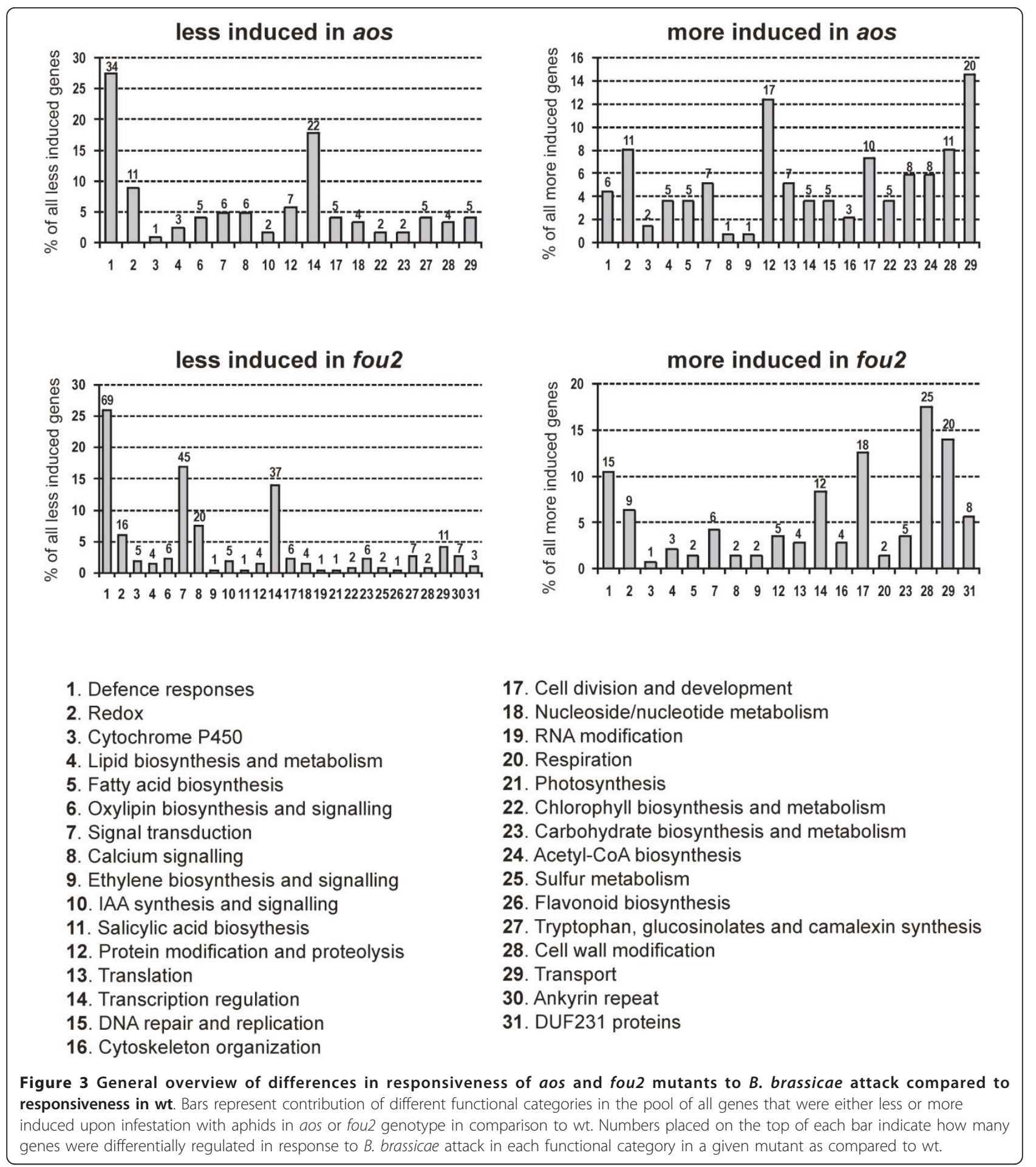

among genes less responsive to aphid attack both in aos and fou 2 mutants (Figure 4A, C). These categories taken together contributed almost half of the genes whose responsiveness was negatively affected in aos and fou 2 plants (Figure 3). Although the majority of the genes that responded to $B$. brassicae infestation in wt plants were induced in the challenged aos as well, their regulation was weaker in the mutant than in wt (Additional file 5 Table S3). Twenty two genes, whose products are involved in regulation of transcription and 34 transcripts connected to defence showed no induction or weaker up-regulation upon infestation in the aos mutant. Several 


\section{A) Genes less induced in response to $B$. brassicae attack in aos and fou 2 than in wt}

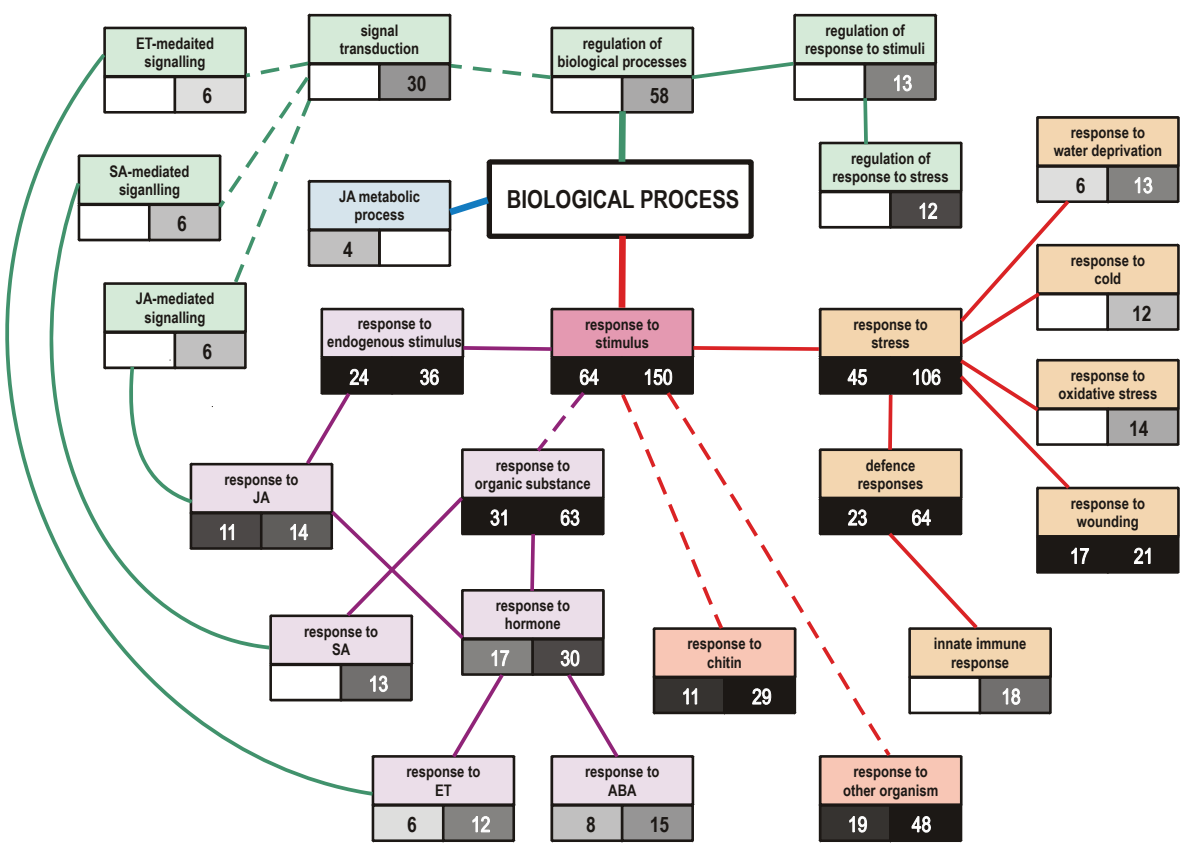

B) Genes more induced in response to $B$. brassicae attack in aos and fou 2 than in wt

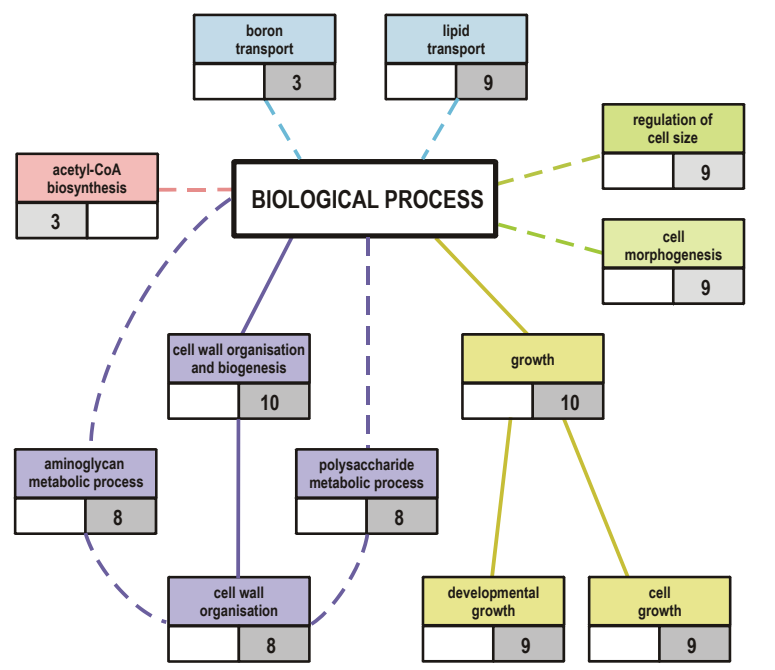

C) Genes less induced in response to $B$. brassicae attack in aos and fou 2 than in wt

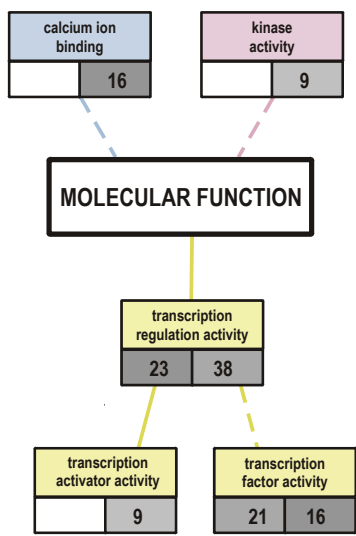

Figure 4 Simplified graphic representation of enriched GO terms connected to biological process or molecular function in genes that were less (A, C) or more (B) induced compared to wt in their response to Brevicoryne brassicae attack in aos and fou 2 mutants. The graph is based on results generated by AmiGO Term Enrichment [31] of functional gene networks. Functionally connected GO categories are represented with the same colour code. Streaked lines indicate that GO terms that exist between the two connected GO terms were omitted from presentation for clarity reasons. Only GO terms classified as enriched according to AmiGO Term Enrichment (with $p$ value $<0.05$ ) are presented in the graph. The numbers of genes attributed to a given $\mathrm{GO}$ term for aos and fou2 mutants are indicated in the left and right boxes under given GO terms, respectively. A darker shade of grey corresponds to higher significance of enrichment (lower $p$ value) of a given GO term according to the AmiGO Term Enrichment analysis. 
transcription factors and defence-related proteins were, in contrast to wt, either not induced or down-regulated in the aphid-challenged aos plants; i.e. BTB and TAZ domain protein 5 (BT5), dehydration-responsive elementbinding protein $2 A$ (DREB2A), ethylene-responsive transcription factors ERF11 and ERF13, myb family transcription factor (MYB50), C2H2 type family protein, DARK INDUCIBLE 11 (DIN11), sulfotransferase family protein (At5g07010), strictosidine synthase, plant defensine 1 $(P D F 1)$, cysteine-rich antifungal protein 1 precursor (AFP1), heat shock protein 81-1 (HSP81-1) and arginase. These observations clearly show that JA signalling is important in the activation of defensive responses triggered by $B$. brassicae attack. However, the fact that some genes were up-regulated during infestation despite of the lack of AOS enzyme activity indicates that JA signalling is, as expected, not the only system controlling gene regulation. Interestingly, some of the defence-related transcripts (e.g. PR1, HR3, disease resistance genes: At1g57630, At3g25010, At2g47800) accumulated in the non-challenged aos plants as compared to wt, probably as a result of stress connected to the lack of JA or an imbalance between JA and SA signalling pathways.

In the fou 2 mutant, several transcription factors and defence-related genes were already up-regulated in nonchallenged plants compared to wt, indicating constant activation of defence caused by the increased endogenous JA levels [e.g. WRKY, ethylene responsive transcription factors, zinc finger family proteins, pathogenesis related proteins PR1 and PR2, enhanced disease susceptibility 5 (EDS5), protease inhibitors, cysteine-rich antifungal proteins: PDF1.1, PDF1.2, PDF1.2b PDF1.2c, PDF1.3, DARK INDUCIBLE 11 (DIN11)]. Often the induction of these genes was stronger in non-challenged fou 2 mutants in comparison to wt than in the infested wt compared to aphid free wt. In such cases no additional induction was noted in the aphid-attacked fou 2 mutant compared to the aphid-free fou 2 control. For other genes a slight additional induction of already up-regulated transcripts was observed in fou 2 plants attacked by B. brassicae (Additional file 7 Table S5). Out of 41 transcription factors and 74 defencerelated genes up-regulated upon $B$. brassicae infestation in wt, but having changed aphid-triggered regulation in one or both mutants, 37 and 69 genes, respectively, were less up-regulated or not induced in the fou 2 mutant in response to infestation. These results indicate that the activation of defence responses may have an overall induction threshold. A potential for an additional, aphid-triggered induction is likely limited when the basal activation of transcripts in non-challenged fou 2 plants is already very high.

Several senescence-associated genes responded to aphid attack with strong induction. Overall, the intensity of aphid-induced changes in this group of genes was similar in wt and aos plants, but slightly weaker in the fou 2 mutant. Thus JA signalling seems not to be the key factor controlling the expression of senescence-associated genes upon infestation.

\section{Stress signalling in aphid-attacked plants is moderately weaker in the JA-deficient mutant}

Proteins involved in the perception of stress and transduction of signals play an important role in the initiation of defence responses [7]. After $72 \mathrm{~h}$ of sustained aphid infestation a large number of genes coding for proteins involved in calcium signalling, signal transduction and redox changes were up-regulated in the aphid-attacked wt plants.

Similar responses were also triggered in the aos mutant but the average intensity of gene regulation was slightly lower compared to wt. Only transcripts associated with redox processes responded to infestation with higher average induction in aos than in wt plants. These observations indicate that the JA-deficient mutant is not impaired in the perception and transduction of signals during infestation and that JA signalling plays only a partial role in the activation of these processes.

In contrast, the aphid-triggered responsiveness of genes connected to stress signalling was reduced in the fou 2 mutant. The GO category denoted "regulation of biological processes", which included "regulation of response to stimuli" and "signal transduction", was statistically significantly enriched as indicated by the GO Term Enrichment analysis of genes that were less responsive to infestation in the fou 2 mutant (Figure 4A). Signal transduction, calcium signalling and redox gene categories were also abundantly represented among genes that were less induced by infestation in fou 2 than in wt (Figure 3). The expression of 45 , 20 and 16 genes related to respective functional categories were either not changed, changed to a lesser extent than in wt or were oppositely regulated in response to infestation in fou 2 plants (Additional file 7 Table S5). However, some of these genes were up-regulated in the non-challenged fou 2 mutant in comparison to wt [e.g. calciumbinding EF-hand: CML38, CML41, CaMBP25, blue copper-binding, DSBA oxidoreductase family gene, monodehydroascorbate reductase (MDAR1), glutaredoxin family protein (GRX480), thioredoxin H-type 5 (TRX5), FADlinked oxidoreductase, peroxidase 32 precursor (PER32)]. Thus, processes connected to the perception and transduction of signals seem to be imbalanced in the non-challenged fou 2 mutant and their activation upon aphid infestation might be impaired.

\section{Changed JA status leads to the induction of genes connected to transport and cell wall modifications}

Both aos and fou 2 mutants responded to infestation by up-regulation of genes linked to transport, while the 
average expression profile of these genes in wt plants remained unchanged after $B$. brassicae attack. GO Term Enrichment analysis indicated that mainly GO terms connected to boron and lipid transport were effected in fou 2 (Figure 4B). It is possible that in response to infestation, plants in which the JA synthesis rate is somehow disturbed (either from a lack of JA in aos or an overproduction of JA-related compounds in fou2) try to compensate for unbalanced JA signalling by induction of cellular transport.

Interestingly, some genes whose products are involved in cell wall modification were differentially regulated upon infestation in the mutant plants in comparison to wt. These genes also make a considerable contribution to the set of all genes that were more induced by aphid attack in aos and fou 2 mutants than in wt (Figure 3). As revealed by AmiGO Term Enrichment analysis, GO terms connected to cell wall organization and aminoglycan and polysaccharide metabolic processes are overrepresented in the set of genes that were more induced by aphid attack in the fou 2 mutant (Figure 4B). Generally these genes were slightly down-regulated in the aphidchallenged wt plants, not responsive in infested aos and slightly up-regulated in infested fou 2 . Their expression was not changed in aphid-free mutants as compared to wt. Thus, it seems that hyper-activation of the JA signalling pathway in the fou 2 mutant might cause some changes in cell walls that do not occur in the infested wt plants.

\section{The fou 2 mutation increases plant resistance to Brevicoryne brassicae by a mechanism other than feeding deterrence}

The relative susceptibility of aos, fou 2 and wt plants to infestation with $B$. brassicae was evaluated in aphid fitness experiments. First instar nymphs were placed on each of the three genotypes and their asexual fecundity was monitored simultaneously. After 13 days the number of offspring did not differ significantly between aos and Col-0 plants. However, aphid fecundity on the fou 2 mutant was significantly lower when compared to the fecundity observed on aos and wt plants (Figure 5). To further investigate whether some anti-xenotic (feeding deterrent) factors are involved in the observed resistance of fou 2 to B. brassicae, we employed the Electrical Penetration Graph (EPG) technique. EPG allowed us to monitor and compare the amount of time the aphids spent on various activities connected to the penetration of plant tissue and ingestion of phloem sap on fou 2 mutants and wt plants. The electrical waveforms, corresponding to non-probing (when the stylet does not have any contact with plant tissue), pathway (where the stylet is manoeuvred through plant tissue accompanied by sheath salivary discharges), the sieve element phase

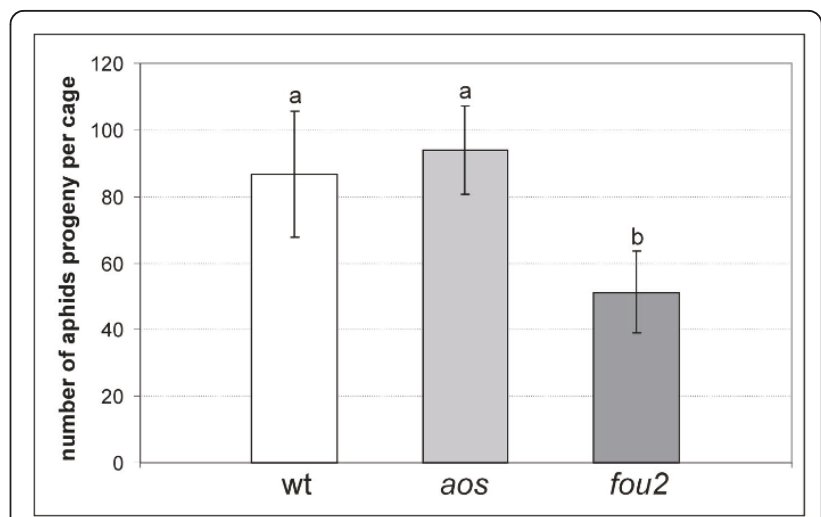

Figure 5 Asexual fecundity of Brevicoryne brassicae on wt Col$\mathbf{0}$, aos and fou 2 plants. Initially two first instar nymphs were placed on each of the three plants kept in the same cage during the experiment. In total, 11 cages (33 plants) of each of the genotypes were used in the experiment. Bars represent an average number (+/- SD) of aphid progeny per cage after 13 days. Different letters indicate statistically significant differences between the numbers of newborn aphids on different genotypes as revealed by a two-tailed Wilcoxon rank sum test.

(called SEP, when the stylet is located in a sieve element), and xylem phase (when the stylet is located in a xylem cell) were recorded for $8 \mathrm{~h}$ and categorized according to known wave patterns corresponding to each activity. The average time spent on each activity was calculated separately for aphids feeding on fou 2 and wt plants. The time aphids spent on non-probing, pathway, and SEP was similar in the case of fou 2 and wt plants (Figure 6). As phloem sap uptake from fou 2 mutants was not restricted, we conclude that feeding

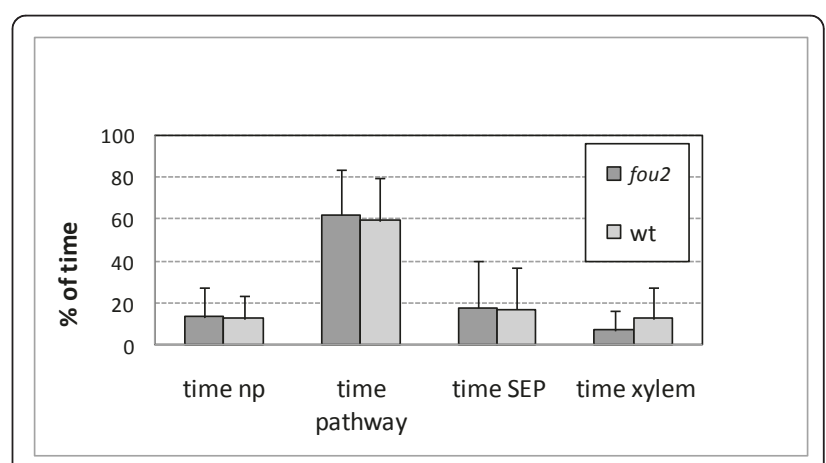

Figure 6 The relative amount of time spent on different feeding behaviours by Brevicoryne brassicae on fou 2 and wt plants as revealed by Electrical Penetration Graph recordings during $\mathbf{8}$ hours-long experiments. Abbreviations: time $\mathrm{np}$, time spent on plant without physical contact between stylet and plant tissue; time pathway, time spent on penetration of plant tissue by stylet; time SEP, time spent on feeding from sieve element; time xylem, time spent on feeding from xylem. None of the observed differences was statistically significant (Wilcoxon rank sum test). 
deterrence was not the factor limiting B. brassicae population size on fou 2 plants.

\section{Discussion}

JA signalling contributes to aphid-triggered regulation of a wide range of genes

Several experiments have proven that infestation with phloem feeders leads to extensive transcriptional reprogramming of the attacked plants. Gene expression changes manifested in the current experiment in wt plants $72 \mathrm{~h}$ after infestation with $B$. brassicae correspond well to the changes previously observed in different $A$. thaliana ecotypes attacked by green peach aphid (Myzus persicae) or B. brassicae [9]. Although such a long period of infestation may cause secondary effects linked to withdrawal of significant amounts of amino acids and sugars contained in the phloem sap, most of the transcriptional changes were similar to those observed in earlier phases of infestation (e.g. $48 \mathrm{~h}, 24 \mathrm{~h}$, or even $12 \mathrm{~h}$ ) [7]. This indicates that there is no dramatic change in the type of responses activated $72 \mathrm{~h}$ after aphid attack as compared to earlier stages of infestation.

Jasmonates are physiological signals for defence. The enhanced production of JA in response to pathogen and insect attack regulates expression of many defencerelated genes and may induce broad-spectrum resistance [32]. Interestingly, many of the genes that were up-regulated in response to infestation in wt plants have shown similar induction in the non-challenged fou 2 mutant. Characterization of fou 2 by Bonaventure and co-workers revealed strong induction of defensive mechanisms resulting from overproduction of JA [33]. Other studies have demonstrated that the application of methyl jasmonate also causes activation of the JA pathway and similar up-regulation of genes connected to defence, responses to oxidative stress, and cell wall modification [34-36]. Similar changes have also been detected at the protein level [37]. Although plants that are deficient in the production of JA do not show any symptoms of disease when grown under laboratory conditions, our study clearly shows that lack of JA negatively influences the basal expression of a wide range of genes. As expected, many of these genes encode proteins that are directly or indirectly involved in plant defence. A number of JAdependent defence-related transcripts were induced in wt plants during $B$. brassicae attack, but only a few of these were activated in the challenged aos mutant, which showed that the regulation of these genes upon aphid attack is primarily controlled through JA signalling. Aphid-mediated induction of many other genes was clearly affected by the aos mutation as well. Although the transcription of many of these genes was apparently not dependent on the JA status in non-challenged plants, JA-derived signals comprised a significant contribution to their regulation in infested plants. Aphid-induced changes in the expression of a number of transcription factors such as WRKY, C2H2 zinc fingers, BTB and TAZ domain containing proteins and ERFs were weaker in aos than in wt, indicating the importance of JA for their induction. WRKY transcription factors are important in SA-dependent defence and some are implicated in cross-talk between JA and SA signalling [38]. Transcription factors containing ethylene responsive domains have been shown to be regulated by JA $[39,40]$ and to participate in plant stress responses [41-43]. They may integrate ET- and JA-derived signals, possibly by interaction with the GCC box in the promoter region of JA-regulated genes [44] and act as both positive and negative regulators of transcriptional changes [39]. Transcription factors such as AP2-domain protein ERF018/ORA47, ZAT10 and AZF2 have been previously identified as both positive and negative regulators of JA signalling [45]. However, their involvement in the activation of plant defence has not been assessed yet. Strong up-regulation of these genes in wt plants attacked by $B$. brassicae suggests that they play an important role in defence against aphids. The regulatory function of BTB and TAZ domain containing proteins has not been established yet, but BTB and TAZ domain protein (BT2) have been identified as essential components of the TELOMERASE ACTIVATOR1 (TAC1)mediated telomerase activation pathway [46]. Telomerase activity is high in plants in rapidly dividing cells and reproductive organs. The induction of $\mathrm{BT} 2$ and $\mathrm{BT} 5$ in the non-challenged aos plants suggests that these genes are under negative regulation of JA. All five BTB and TAZ proteins (BT1-BT5) are known to be readily induced by $\mathrm{H}_{2} \mathrm{O}_{2}$ and SA treatments [47].

The glutaredoxin family protein GRX480, whose induction was eliminated in the infested aos plants, was recently identified as a regulator of JA/SA cross talk. It interacts with TGA transcription factors to antagonize expression of JA-responsive genes in an NPR1-dependent manner [48]. Our results indicate that the induction of GRX480 upon B. brassicae attack is dependent on JA levels.

The expression of EDS5 in both non-challenged and aphid-attacked plants shows that JA levels also influence it. This is in contrast to previous reports, which describe solitary SA signalling based regulation of the EDS5 gene [49]. Our results suggest that regulation of EDS5 is more complex than previously thought.

\section{Additional signals are involved in regulation of the response to $B$. brassicae infestation}

Some genes, whose expression in non-challenged plants was clearly dependent on JA responded to infestation in the aos mutant despite the lack of JA-derived signals, 
even though their induction was not as extensive as the induction observed in wt plants. This indicates that, in addition to JA, some other signalling mechanisms are involved in the regulation of these transcripts upon $B$. brassicae infestation. It is well established that the activation of invader-specific responses in plants attacked by insects is mediated by cross-talk between different signalling pathways [38]. In the case of insect infestation, in addition to JA, phytohormones such as salicylic acid (SA), ethylene (ET) and abscisic acid (ABA) play major roles in coordinating the induction of appropriate defences $[26,50]$. Thus SA, ET or ABA are likely regulators of the defence responses in the absence of JA for genes such as trypsin inhibitors (ATTI1 and At1g73260), TAT3, CYP79B2, PR4 or ASA1.

\section{Induction of JAZ repressors desensitizes fou2 response to B. brassicae attack}

The transcriptional profile of the non-challenged fou 2 genotype mimics the profile of wt plants that manifest induced defence [33]. In our studies many of the genes that have been shown to be involved in the response to aphid attack in wt plants were up-regulated in the nonchallenged fou 2 mutant, often showing similar or stronger intensity of changes compared to attacked wt plants (Table 1 and Additional file 7 Table S5). A similar induction of transcription factors and defence-related genes was observed by Bonaventure and co-workers [33]. However, in contrast to the previously observed reaction of fou 2 to wounding [17], further induction of these transcripts upon infestation was much weaker than observed in wt plants. A similar lack of stress responses resulting from prolonged high endogenous JA levels was observed in potato plants subjected to wounding and water stress. Although several of the genes involved in JA biosynthesis are induced by JA thereby creating a positive feedback loop [51], there exists also a negative regulatory feedback loop protecting the plants from the adverse effects of their own defence. The constitutive up-regulation of the JA synthesis pathway in the fou 2 mutant probably triggers this negative feedback loop, leading to desensitization of processes involved in the activation of the aphid-induced defence. JAZ family proteins act to repress transcription of JA-inducible genes and thus modulate JA-mediated plant responses [52,53]. The high induction of several $J A Z$ genes in the fou 2 mutant (Additional file 3 Table S1) indicates activation of the desensitization mechanism and may explain the reduced responsiveness of fou 2 plants challenged with $B$. brassicae. The negative regulation of JA responses is delayed and takes effect some time after the proceeding induction [45]. The hyper activation of JA biosynthesis genes in fou 2 plants shortly after mechanical wounding that was observed by Bonaventure and co-workers [17] was not observed by us after $72 \mathrm{~h}$ of sustained B. brassicae infestation. This might be due to a stealthy manner of aphid feeding that causes only minimal tissue damage. The induction of the wound-specific JA responses in aphid-infested plants is therefore much weaker than in mechanically wounded plants. In addition, the high level of JAZ repressors may also tune the JA-regulated transcriptional changes in the aphid-attacked fou 2 plants after $72 \mathrm{~h}$.

\section{Aphid fitness is comparable on wt and aos genotypes but reduced on fou 2}

Despite the reduced responsiveness of a wide range of defence-linked genes in the aos mutant, we did not observe any improvement in aphid fitness in comparison to wt plants. This may seem surprising as JA signalling seems to be important for plant defence mechanisms induced upon infestation. In contrast to our results, Ellis and co-workers observed increased growth of green peach aphid (Myzus persicae) populations on the coi1-16 mutant that had defects in JA signalling [13]. However the coi1-16 line carries an additional mutation that might have influenced $M$. persicae responses observed by Ellis and co-workers. This mutation lies in the PENETRATION2 (PEN2) gene encoding a glycoside hydrolase and renders the PEN2 protein with highly reduced stability [54]. PEN2 is required for indole glucosinolatedependent pathogen-induced callose deposition [55]. As accumulation of callose is one of the defence mechanisms against aphid infestation [7], the pen2-4 mutation, present in coi1-16 line, may contribute to the increased susceptibility of coil-16 plants to infestation with M. persicae.

It is also conceivable that the expressional changes of JA-regulated genes observed by us in the aphid-infested aos mutant were sufficient to sustain the same level of aphid resistance/susceptibility as is present in wt plants. It should be noted that many genes known to be regulated by SA, ABA or auxin signalling were up-regulated in aos plants. Several of these can be involved in defence against $B$. brassicae infestation and influence aphid fitness.

As revealed by the insect fitness tests, physiological changes resulting from the fou 2 mutation render plants more resistant to infestation than wt, despite the reduced intensity of the aphid-induced responses. As the observed resistance was not based on feeding deterrence, it is most probably based on antibiosis. Various defence-related responses that are constitutively activated in fou 2 plants, e.g. high expression of plant defensin proteins (PDFs), pathogenesis-related proteins (PR) or protease inhibitors, can exhibit an antibiotic effect on insect pests. The latter, for example, can disturb digestion and absorption of food in the insect gut [27]. Moreover, the high activity of LOX enzyme in fou 2 plants can increase production of reactive lipid peroxides, cause oxidative damage to the insect gut 
and significantly decrease the nutritive quality of dietary proteins [56]. It should be noted, however, that the mechanism responsible for the manifestation of the fou 2 phenotype is not fully understood. Therefore, we cannot eliminate the possibility that other, unknown, features of fou 2 could play a role in mediating aphid resistance.

\section{Conclusions}

A comparison of transcriptional profiles of non-challenged aos, fou 2 and wt plants allowed us to identify more than 200 genes whose expression profiles in nonchallenged plants were dependent on endogenous jasmonate status. Most of these transcripts were up-regulated in fou 2 and down-regulated in aos mutants, which points to a positive regulatory function of JA-derived compounds. Many of the jasmonate-dependent genes were connected to regulation of transcription, defence responses, redox balance and cell wall modification.

Upon infestation with Brevicoryne brassicae, the responsiveness of many genes was changed in aos and fou 2 plants. Genes attributed to GO categories connected to the regulation of transcription and responses to stress were generally less induced in both mutants. In contrast, transcripts classified as involved in cell division and development, cell wall modification and transport were more induced or not as much down-regulated in the mutants compared to wt. The observed changes in aphid-mediated responsiveness of aos had, however, no noticeable impact on aphid fitness. This may indicate that the induced responses, although weaker than in wt, were strong enough to keep the same level of resistance. Alternatively, responses were mainly induced locally, so that the aphids could benefit from frequent changes of feeding places. In the fou 2 mutant, several genes involved in defence against $B$. brassicae were induced in non-challenged plants. As a consequence, the transcriptional profile of non-challenged fou 2 resembled the aphid-induced profile of wt. Although additional $B$. brassicae mediated regulation of already induced genes was limited, the aphids' reproduction rate was negatively influenced by the fou 2 mutation. As an array of defensive responses is constitutively activated in fou 2 plants, the feeding aphids could not move to a leaf area where the response was not induced, as they could in the case of wt plants.

Our results indicate that JA-regulated responses are important in defining susceptibility of a plant to infestation with aphids. As shown in this study, JA-derived compounds are powerful regulators of a range of defensive responses exhibited by plants attacked by aphids.

\section{Methods}

\section{Plant material}

The Arabidopsis thaliana Columbia-0 ecotype (Col-0) single seeds line used in the experiment has been derived from seeds produced by Lehle Seeds (Round Rock, USA; Catalogue No. WT-2-8, Seed Lot No. GH195-1). The aos mutant was the one described in [15]. The fou 2 mutant was kindly donated by Prof. Edward Farmer (University of Lausanne, Switzerland). Both mutants are in Col-0 background. Seeds were sterilized according to standard procedures and plants were initially grown aseptically on agar medium containing MS basal salt mixture (Sigma), 3\% (v/w) sucrose, and $0.7 \%(\mathrm{v} / \mathrm{w})$ agar ( $\mathrm{pH} 5.7)$ to assure uniform germination. After 15 days, seedlings were moved to $6 \mathrm{~cm}$ diameter pots ( 3 seedlings per pot) filled with a sterile soil mix (1.0 part soil, and 0.5 part horticultural perlite). Plants were kept in growth chambers Vötsch VB 1514 (Vötsch Industrietechnik $\mathrm{GmbH}$, Germany) under the following conditions: a $8 / 16 \mathrm{~h}$ (light/dark) photoperiod at $22^{\circ} \mathrm{C} /$ $18^{\circ} \mathrm{C}, 40 \% / 70 \%$ relative humidity, and $70 / 0 \mu \mathrm{mol} \mathrm{m} \mathrm{m}^{-2}$ light intensity. A short time day was applied to prevent plants from bolting. For aphid fitness experiments, plants were sown directly to pots with soil (one plant per pot) and kept in chambers under a 16/8 h (light/ dark) photoperiod.

\section{Insects}

Brevicoryne brassicae was reared on Brassica napus or Brassica oleracea plants in a growth chamber with a $16 /$ $8 \mathrm{~h}$ (light/dark) photoperiod at $22^{\circ} \mathrm{C} / 18^{\circ} \mathrm{C}, 40 \% / 70 \%$ relative humidity, and $70 / 0 \mu \mathrm{mol} \mathrm{m} \mathrm{m}^{-2}$ light intensity.

\section{Infestation experiments}

Thirty-two-day-old plants (17 days after transferring to soil) had 8 fully developed leaves. Each plant was infested with 32 wingless aphids (4 per leaf), which were transferred to leaves with a fine paintbrush. Infested plants and aphid-free controls were kept in plexiglass cylinders as described in [9]. Plants were harvested $72 \mathrm{~h}$ after infestation between the 6th and 8th hour of the light photoperiod. Four biological replicates were run, each sampled from 15 individual plants. Whole rosettes were cut at the hypocotyls and aphids were removed by washing with Milli-Q-filtered water. Harvested material was immediately frozen in liquid nitrogen.

\section{RNA isolation, cDNA synthesis and microarray experiments}

All procedures were done as described in [7]. Customdesigned, full genome Arabidopsis oligonucleotide microarrays printed at the Norwegian Microarray Consortium (Trondheim, Norway) were used in all experiments.

\section{Quantitative real-time PCR}

For qRT-PCR analysis, the total RNA was DNAse treated using DNA-free ${ }^{\mathrm{TM}}$ Kit (Applied Biosystems), while the QuantiTect ${ }^{\circledR}$ kit (QIAGEN) was used for cDNA 
synthesis. A LightCycler 480 System and the corresponding SYBR Green I Master mix (Roche Diagnostics $\mathrm{GmbH}$ ) were used in a three-step programme including (1) preincubation at $95^{\circ} \mathrm{C}$ for $5 \mathrm{~min}$; (2) 40 cycles of amplification consisting of $95^{\circ} \mathrm{C}$ for $10 \mathrm{~s}, 55^{\circ} \mathrm{C}$ or $60^{\circ} \mathrm{C}$ for $10 \mathrm{~s}$ and $72^{\circ} \mathrm{C}$ for $10 \mathrm{~s}$; and (3) melting curve analysis by heating from $65^{\circ} \mathrm{C}$ to $97^{\circ} \mathrm{C}$ with a ramp rate of $2.2^{\circ} \mathrm{C} / \mathrm{s}$. Each $20 \mu \mathrm{l}$ reaction contained $0.5 \mu \mathrm{M}$ of each forward and reverse primer (for gene-specific primer sequences used in qRT-PCR, see Additional file 9 Table S7), and cDNA quantity corresponding to $50 \mathrm{ng}$ of RNA. LinRegPCR software [57] was used to determine the PCR reaction efficiency for each sample and the efficiencies for each primer set were calculated by averaging the efficiency values obtained from the individual samples. Relative expression ratios of the targeted genes were calculated and normalized to TIP41-like gene (At4g34270) [58] with the use of REST 2008 software [59]. The qRT-PCR analysis was performed with the use of three biological replicates.

\section{Statistical analysis of microarray data}

The microarray experiment was a 2-by-3 factorial, with the factors as plant type (wt, aos mutant or fou 2 mutant) and treatment (infested or not infested). Each experimental condition, i.e. each combination of factors, was represented by four biological replicates. Seven different direct comparisons of the experimental conditions, using four replicates (each representing 15 individual plants) for each comparison, were made with the use of microarray data sets. However, only data from microarrays with very good technical quality were used for further analyses. (Figure 1 shows the direct comparisons that were made and the comparisons for which only three replicates were of good enough technical quality). Note that using this setup means that the same biological replicate will occur on two different microarrays. Also note that experimental conditions that were not compared directly can still be contrasted, but with lower efficiency than the direct comparisons.

The microarray data for each array were filtered and normalized as discussed in [7]. To make statistical inferences about differential regulation between experimental conditions, the limma package [60] was used. In each comparison of experimental conditions a q-value [61] was calculated for each gene. For a gene to be considered differentially regulated at a statistically significant level, its qvalue had to be lower than 0.05 . In effect this controlled the false discovery rate (FDR) [62-64] of the comparison at a 0.05 level.

\section{Aphid fitness experiments}

B. brassicae fitness on aos and fou 2 mutants in comparison to wt Col-0 was evaluated in experiments assessing aphid asexual fecundity. Two first instar nymphs were placed on each plant and plants were placed in plexiglass cages (3 plants per cage). Eleven cages (33 plants) were used for each genotype tested. After 13 days, aphid progeny numbers in each cage were counted. To compare aphid counts for the different plant types, a twotailed Wilcoxon rank sum test was used with a significance level of 0.05 .

\section{Electrical Penetration Graph}

The EPG technique was used to monitor aphid feeding behaviour [65]. An eight-channel GIGA-8 direct current amplifier (Wageningen University, The Netherlands) was used for simultaneous recordings of eight individual wingless Brevicoryne brassicae aphids feeding on eight plants ( 4 wt plants and 4 fou 2 mutants). The aphids originated from a colony kindly donated by Prof. Gary Thompson (Oklahoma State University) propagated on Brassica oleracea plants. Before the start of an experiment, the aphids were starved for $4 \mathrm{~h}$ and immediately before wiring, an individual aphid's dorsum was cleaned of wax with the help of a paintbrush hair, and a thin gold wire $(12.7 \mu \mathrm{m}$ diameter, $2-4 \mathrm{~cm}$ long) was glued to the dorsum with silver paint (Ted Pella). The other end of the wire was connected to an EPG probe and an output wire from the EPG monitor was inserted into the soil in which the plant was rooted. Plants used in EPG experiments were 3 to 4 weeks old, and did not reach the bolting stage. During experiments plants and insets were kept inside a Faraday cage at constant light conditions and $22^{\circ} \mathrm{C}$. The waveform recordings were analysed using the EPG analysis software PROBE 3.0 (W.F. Tjallingii, Wageningen University, The Netherlands). The experiments were repeated several times to obtain a total of 30 biological replicates for fou 2 and 34 for wt. A Wilcoxon rank sum test was used to compare the amount of time B. brassiae spent on different feeding behaviours as measured with EPG.

\section{Additional material}

Additional file 1: Figure $\mathrm{S1}$. Consequences of the aos and fou2 mutations on jasmonic acid biosynthesis in planta.

Additional file 2: Figure S2. Verification of microarray data by quantitative RT-PCR.

Additional file 3: Table S1. List of genes whose expression in nonchallenged plants was positively influenced by jasmonates. Gene

expression values for which regulation was not statistically significant are shaded in grey.

Additional file 4: Table S2. List of genes whose expression in nonchallenged plants was negatively influenced by jasmonates. Gene expression values for which regulation was not statistically significant are shaded in grey.

Additional file 5: Table S3. List of genes that were less induced in response to $B$. brassicae infestation in aos than in wt plants. Gene 
expression values for which regulation was not statistically significant are shaded in grey.

Additional file 6: Table S4. List of genes that were more induced in response to $B$. brassicae infestation in aos than in wt plants. Gene expression values for which regulation was not statistically significant are shaded in grey.

Additional file 7: Table S5. List of genes that were less induced in response to $B$. brassicae infestation in fou 2 than in wt plants. Gene expression values for which regulation was not statistically significant are shaded in grey.

Additional file 8: Table S6. List of genes that were more induced in response to $B$. brassicae infestation in fou 2 than in wt plants. Gene expression values for which regulation was not statistically significant are shaded in grey.

Additional file 9: Table S7. Primers used in quantitative RT-PCR analysis.

\section{Acknowledgements}

The authors thank Torfinn Sparstad, Bente Halvorsen, Elisabeth Hyldbakk and Marianne Bakke Nilsen for excellent technical assistance, Wacek Kuśnierczyk for statistical analysis of EPG data and Ralph Kissen for comments on the manuscript. We are grateful to Prof. Edward Farmer (University of Lausanne, Switzerland) for fou2 seeds and Prof. Gary Thompson (Oklahoma State University) for donating a B. brassicae colony for EPG experiments. We also thank in particular Dr. Murugan Marimuthu (Kansas State University) for the help with establishing and learning the EPG technique, Prof. Kathrin Schrick (Kansas State University) for offering space in growth chambers and Predeesh Chandran (Kansas State University) for help with maintaining the plants. This work was supported by the Biotechnology and Functional genomics (FUGE) programmes of the Norwegian Research Council through grants NFR 184146, 164583, 186903, 185173 and US North Central Soybean Research Program.

\section{Author details}

'Department of Biology, The Norwegian University of Science and Technology, Realfagbygget, 7491 Trondheim, Norway. ${ }^{2}$ Scanpower AS, 7462 Trondheim, Norway. ${ }^{3}$ Department of Entomology, Kansas State University, Manhattan, KS 66506, USA. ${ }^{4}$ Department of Plant Physiology, University of Technology and Agriculture, Bernardyńska 6, 85-029 Bydgoszcz, Poland.

\section{Authors' contributions}

AK, PW, TSJ and AMB designed the study. AK, DHTT and JT performed infestation experiments for microarray analyses. TSJ performed statistical analysis of transcriptional data. AK, DHTT and PW analysed the transcriptional data. AK performed aphid fitness and EPG experiments and analysed EPG data. JCR contributed with EPG equipment and coordinated EPG experiments. AK, DHTT and PW wrote the manuscript. AMB coordinated the study and completed the submission. All authors read and approved the final version of manuscript.

Received: 9 November 2010 Accepted: 19 August 2011 Published: 19 August 2011

\section{References}

1. Turner JG, Ellis C, Devoto A: The jasmonate signal pathway. Plant Cell 2002, 14:S153-S164.

2. Howe GA: Jasmonates as signals in the wound response. Journal of Plant Growth Regulation 2004, 23:223-237.

3. Halitschke R, Baldwin IT: Jasmonates and related compounds in plantinsect interactions. Journal of Plant Growth Regulation 2004, 23:238-245.

4. Pozo MJ, Van Loon LC, Pieterse CMJ: Jasmonates-signals in plant-microbe interactions. Journal of Plant Growth Regulation 2004, 23:211-222.

5. Gao LL, Anderson JP, Klingler JP, Nair RM, Edwards OR, Singh KB: Involvement of the octadecanoid pathway in bluegreen aphid resistance in Medicago truncatula. Molecular Plant-Microbe Interactions 2007, 20:82-93.

6. Gosset V, Harmel N, Gobel C, Francis F, Haubruge E, Wathelet JP, du Jardin P, Feussner I, Fauconnier ML: Attacks by a piercing-sucking insect
(Myzus persicae Sultzer) or a chewing insect (Leptinotarsa decemlineata Say) on potato plants (Solanum tuberosum L.) induce differential changes in volatile compound release and oxylipin synthesis. Journal of Experimental Botany 2009, 60:1231-1240.

7. Kuśnierczyk A, Winge P, Jørstad TS, Troczyńska J, Rossiter JT, Bones AM: Towards global understanding of plant defence against aphids-timing and dynamics of early Arabidopsis responses to cabbage aphid (Brevicoryne brassicae) attack. Plant, Cell and Environment 2008, 31:1097-1115.

8. Park SJ, Huang YH, Ayoubi P: Identification of expression profiles of sorghum genes in response to greenbug phloem-feeding using CDNA subtraction and microarray analysis. Planta 2006, 223:932-947.

9. Kuśnierczyk A, Winge P, Midelfart H, Armbruster WS, Rossiter JT, Bones AM: Transcriptional responses of Arabidopsis thaliana ecotypes with different glucosinolate profiles after attack by polyphagous Myzus persicae and oligophagous Brevicoryne brassicae. Journal of Experimental Botany 2007, 58:2537-2552.

10. Kempema LA, Cui XP, Holzer FM, Walling LL: Arabidopsis transcriptome changes in response to phloem-feeding silverleaf whitefly nymphs. Similarities and distinctions in responses to aphids. Plant Physiology 2007, 143:849-865.

11. Zhu-Salzman K, Salzman RA, Ahn JE, Koiwa H: Transcriptional regulation of sorghum defense determinants against a phloem-feeding aphid. Plant Physiology 2004, 134:420-431.

12. Zarate SI, Kempema LA, Walling LL: Silverleaf whitefly induces salicylic acid defenses and suppresses effectual jasmonic acid defenses. Plant Physiology 2007, 143:866-875.

13. Ellis C, Karafyllidis L, Turner JG: Constitutive activation of jasmonate signaling in an Arabidopsis mutant correlates with enhanced resistance to Erysiphe cichoracearum, Pseudomonas syringae, and Myzus persicae. Molecular Plant-Microbe Interactions 2002, 15:1025-1030.

14. Xie DX, Feys BF, James S, Nieto-Rostro M, Turner JG: COl1: An Arabidopsis gene required for jasmonate-regulated defense and fertility. Science 1998, 280:1091-1094

15. Park JH, Halitschke R, Kim HB, Baldwin IT, Feldmann KA, Feyereisen R: A knock-out mutation in allene oxide synthase results in male sterility and defective wound signal transduction in Arabidopsis due to a block in jasmonic acid biosynthesis. Plant Journal 2002, 31:1-12.

16. Laudert D, Pfannschmidt U, Lottspeich F, Hollander-Czytko H, Weiler EW: Cloning, molecular and functional characterization of Arabidopsis thaliana allene oxide synthase (CYP 74), the first enzyme of the octadecanoid pathway to jasmonates. Plant Molecular Biology 1996, 31:323-335.

17. Bonaventure G, Gfeller A, Proebsting WM, Hortensteiner S, Chetelat A, Martinoia E, Farmer EE: A gain-of-function allele of TPC1 activates oxylipin biogenesis after leaf wounding in Arabidopsis. Plant Journal 2007, 49:889-898.

18. Peiter E, Maathuis FJM, Mills LN, Knight $H$, Pelloux M, Hetherington AM, Sanders D: The vacuolar $\mathrm{Ca}^{2+}$-activated channel TPC1 regulates germination and stomatal movement. Nature 2005, 434:404-408.

19. Moran PJ, Cheng YF, Cassell JL, Thompson GA: Gene expression profiling of Arabidopsis thaliana in compatible plant-aphid interactions. Archives of Insect Biochemistry and Physiology 2002, 51:182-203.

20. Moran PJ, Thompson GA: Molecular responses to aphid feeding in Arabidopsis in relation to plant defense pathways. Plant Physiology 2001, 125:1074-1085.

21. De Vos M, Van Oosten VR, Van Poecke RMP, Van Pelt JA, Pozo MJ, Mueller MJ, Buchala AJ, Metraux JP, Van Loon LC, Dicke M, Pieterse CMJ. Signal signature and transcriptome changes of Arabidopsis during pathogen and insect attack. Molecular Plant-Microbe Interactions 2005, 18:923-937.

22. Kehr J: Phloem sap proteins: their identities and potential roles in the interaction between plants and phloem-feeding insects. Journal of Experimental Botany 2006, 57:767-774.

23. Kim JH, Jander $\mathrm{G}$ : Myzus persicae (green peach aphid) feeding on Arabidopsis induces the formation of a deterrent indole glucosinolate. Plant Journal 2007, 49:1008-1019.

24. Mewis I, Appel HM, Hom A, Raina R, Schultz JC: Major signaling pathways modulate Arabidopsis glucosinolate accumulation and response to both phloem-feeding and chewing insects. Plant Physiology 2005, 138:1149-1162. 
25. Mewis I, Tokuhisa JG, Schultz JC, Appel HM, Ulrichs C, Gershenzon J: Gene expression and glucosinolate accumulation in Arabidopsis thaliana in response to generalist and specialist herbivores of different feeding guilds and the role of defense signaling pathways. Phytochemistry 2006, 67:2450-2462.

26. Thompson GA, Goggin FL: Transcriptomics and functional genomics of plant defence induction by phloem-feeding insects. Journal of Experimental Botany 2006, 57:755-766.

27. Zhu-Salzman K, Luthe DS, Felton GW: Arthropod-inducible proteins: broad spectrum defenses against multiple herbivores. Plant Physiology 2008, 146:852-858.

28. Smith CM, Boyko EV: The molecular bases of plant resistance and defense responses to aphid feeding: current status. Entomologia Experimentalis et Applicata 2007, 122:1-16.

29. Goggin FL: Plant-aphid interactions: molecular and ecological perspectives. Current Opinion in Plant Biology 2007, 10:399-408

30. De Vos M, Kim JH, Jander G: Biochemistry and molecular biology of Arabidopsis-aphid interactions. Bioessays 2007, 29:871-883.

31. Carbon S, Ireland A, Mungall CJ, Shu S, Marshall B, Lewis S, the AmiGO Hub, the Web Presence Working Group: AmiGO: online access to ontology and annotation data. Bioinformatics 2009, 25:288-289.

32. Devoto A, Turner JG: Regulation of jasmonate-mediated plant responses in Arabidopsis. Annals of Botany 2003, 92:329-337.

33. Bonaventure G, Gfeller A, Rodriguez VM, Armand F, Farmer EE: The fou 2 gain-of-function allele and the wild-type allele of Two Pore Channel 1 contribute to different extents or by different mechanisms to defense gene expression in Arabidopsis. Plant and Cell Physiology 2007, 48:1775-1789.

34. Jung J, Lyou SH, Yeu S, Kim MA, Rhee S, Kim M, Lee JS, Choi YD, Cheong J: Microarray-based screening of jasmonate-responsive genes in Arabidopsis thaliana. Plant Cell Rep 2007, 26:1053-1063.

35. Sasaki-Sekimoto Y, Taki N, Obayashi T, Aono M, Matsumoto F, Sakurai N, Suzuki H, Hirai MY, Noji M, Saito K, Masuda T, Takamiya K, Shibata D, Ohta $\mathrm{H}$ : Coordinated activation of metabolic pathways for antioxidants and defence compounds by jasmonates and their roles in stress tolerance in Arabidopsis. The Plant Journal 2005, 44:653-668.

36. Reymond P, Bodenhausen N, Van Poecke RMP, Krishnamurthy V, Dicke M, Farmer EE: A conserved transcript pattern in response to a specialist and a generalist herbivore. Plant Cell 2004, 16:3132-3147.

37. Chen Y, Pang Q, Dai S, Wang Y, Chen S, Yan X: Proteomic identification of differentially expressed proteins in Arabidopsis in response to methyl jasmonate. Journal of Plant Physiology 2011, 168:995-1008.

38. Koornneef A, Pieters MJ: Cross talk in defense signaling. Plant Physiology 2008, 146:839-844

39. McGrath KC, Dombrecht B, Manners JM, Schenk PM, Edgar Cl, Maclean DJ, Scheible WR, Udvardi MK, Kazan K: Repressor- and activator-type ethylene response factors functioning in jasmonate signaling and disease resistance identified via a genome-wide screen of Arabidopsis transcription factor gene expression. Plant Physiology 2005, 139:949-959.

40. Nakano T, Suzuki K, Ohtsuki N, Tsujimoto Y, Fujimura T, Shinshi H: Identification of genes of the plant-specific transcription-factor families cooperatively regulated by ethylene and jasmonate in Arabidopsis thaliana. Journal of Plant Research 2006, 119:407-413.

41. Jung J, Won SY, Suh SC, Kim H, Wing R, Jeong Y, Hwang I, Kim M: The barley ERF-type transcription factor HvRAF confers enhanced pathogen resistance and salt tolerance in Arabidopsis. Planta 2007, 225:575-588.

42. Onate-Sanchez L, Anderson JP, Young J, Singh KB: AtERF14, a member of the ERF family of transcription factors, plays a nonredundant role in plant defense. Plant Physiology 2007, 143:400-409.

43. Weiste $C$, Iven T, Fischer U, Onate-Sanchez L, Droge-Laser W: In planta ORFeome analysis by large-scale over-expression of GATEWAY (R)compatible cDNA clones: screening of ERF transcription factors involved in abiotic stress defense. Plant Journal 2007, 52:382-390.

44. Brown RL, Kazan K, McGrath KC, Maclean DJ, Manners JM: A role for the GCC-box in jasmonate-mediated activation of the PDF1.2 gene of Arabidopsis. Plant Physiology 2003, 132:1020-1032.

45. Pauwels L, Morreel K, De Witte E, Lammertyn F, Van Montagu M, Boerjan W Inze D, Goossens A: Mapping methyl jasmonate-mediated transcriptional reprogramming of metabolism and cell cycle progression in cultured Arabidopsis cells. Proceedings of the National Academy of Sciences of the United States of America 2008, 105:1380-1385.
46. Ren SX, Mandadi KK, Boedeker AL, Rathore KS, McKnight TD: Regulation of telomerase in Arabidopsis by BT2, an apparent target of TELOMERASE ACTIVATOR1. Plant Cell 2007, 19:23-31.

47. Du LQ, Poovaiah BW: A novel family of $\mathrm{Ca} 2+$ /calmodulin-binding proteins involved in transcriptional regulation: interaction with fsh/Ring 3 class transcription activators. Plant Molecular Biology 2004, 54:549-569.

48. Ndamukong I, Al Abdallat A, Thurow C, Fode B, Zander M, Weigel R, Gatz C SA-inducible Arabidopsis glutaredoxin interacts with TGA factors and suppresses JA-responsive PDF1.2 transcription. Plant Journal 2007, 50:128-139.

49. Nawrath C, Heck S, Parinthawong N, Metraux JP: EDS5, an essential component of salicylic acid-dependent signaling for disease resistance in Arabidopsis, is a member of the MATE transporter family. Plant Cell 2002, 14:275-286.

50. Bodenhausen N, Reymond P: Signaling pathways controlling induced resistance to insect herbivores in Arabidopsis. Molecular Plant-Microbe Interactions 2007, 20:1406-1420.

51. Wasternack C: Jasmonates: An update on biosynthesis, signal transduction and action in plant stress response, growth and development. Annals of Botany 2007, 100:681-697.

52. Chini A, Fonseca S, Fernandez G, Adie B, Chico JM, Lorenzo O, GarciaCasado G, Lopez-Vidriero I, Lozano FM, Ponce MR, Micol JL, Solano R: The JAZ family of repressors is the missing link in jasmonate signalling. Nature 2007, 448:666-671.

53. Thines B, Katsir L, Melotto M, Niu Y, Mandaokar A, Liu GH, Nomura K, He SY, Howe GA, Browse J: JAZ repressor proteins are targets of the SCFCO11 complex during jasmonate signalling. Nature 2007, 448:661-665.

54. Westphal L, Scheel D, Rosahl S: The coi1-16 mutant harbors a second site mutation rendering PEN2 nonfunctional. The Plant Cell 2008, 20:824-826.

55. Clay NK, Adewale MA, Denoux C, Jander G, Ausubel FM: Glucosinolate metabolites required for an Arabidopsis Innate Immune Response. Science 2009, 323:95-101.

56. Felton GW, Bi JL, Summers CB, Mueller AJ, Duffey SS: Potential role of lipoxygenases in defense against insect herbivory. Journal of Chemical Ecology 1994, 20:651-666.

57. Ramakers C, Rujiter JM, Deprez RH, Moorman AFM: Assumption-free analysis of quantitative real-time polymerase chain reaction (PCR) data. Neuroscience Letters 2003, 339:62-66.

58. Czechowski T, Stitt M, Altmann T, Udvardi MK, Scheible WR: Genome-wide identification and testing of superior reference genes for transcript normalization in Arabidopsis. Plant Physiology 2005, 139:5-17.

59. Pfaffl MW, Horgan GW, Dempfle L: Relative expression software tool $\left(\mathrm{REST}^{\odot}\right)$ for group-wise comparison and statistical analysis of relative expression results in real-time PCR. Nucleic acids research 2002, 30:e36.

60. Smyth GK: Limma: linear models for microarray data. Bioinformatics and Computational Biology Solutions using $R$ and Bioconductor New York: Springer; 2005.

61. Storey JD: A direct approach to false discovery rates. Journal of the Royal Statistical Society Series B-Statistical Methodology 2002, 64:479-498.

62. Benjamini $Y$, Hochberg Y: Controlling the false discovery rate-a practical and powerful approach to multiple testing. Journal of the Royal Statistical Society Series B-Methodological 1995, 57:289-300.

63. Jørstad TS, Langaas M, Bones AM: Understanding sample size: what determines the required number of microarrays for an experiment? Trends in Plant Science 2007, 12:46-50.

64. Jørstad TS, Midelfart $\mathrm{H}$, Bones AM: A mixture model approach to sample size estimation in two-sample comparative microarray experiments. BMC Bioinformatics 2008, 9:117.

65. Tjallingii WF: Electrical recording of stylet penetration activities. In Aphids: Their Biology, Natural Anemies and Control. Volume 2B. Edited by: Minks AK, Harrewjin P. Amsterdam: Elsvier; 1988:95-108.

doi:10.1186/1471-2164-12-423

Cite this article as: Kuśnierczyk et al.: Testing the importance of jasmonate signalling in induction of plant defences upon cabbage aphid (Brevicoryne brassicae) attack. BMC Genomics 2011 12:423. 